\title{
Jeffrey Sachs e a Ajuda Oficial para o Desenvolvimento: uma releitura da Teoria da Modernização
}

\section{Jeffrey Sachs and the Official Development Assistance: a rereading of the Modernization Theory}

DOI: $10.21530 /$ ci.v13n3.2018.824

Henrique Zeferino Menezes ${ }^{1}$

Larissa Fernandes Catão ${ }^{2}$

\section{Resumo}

Desde o pós Segunda Guerra Mundial, a Ajuda Oficial para o Desenvolvimento (AOD) tornou-se uma constante nos projetos de desenvolvimento do mundo capitalista para a periferia. Esse instrumento se manteve presente na agenda de desenvolvimento a despeito das mudanças na economia mundial e das críticas sofridas. Nos anos 2000, a AOD se reafirmou política e teoricamente, como meio de implementação dos objetivos de desenvolvimento das Nações Unidas e pela produção acadêmica do economista Jeffrey D. Sachs. Considerando a importância de Sachs na engrenagem da estrutura internacional da AOD, é fundamental um olhar mais atento sobre sua produção intelectual. O objetivo desse artigo é uma análise da perspectiva de Sachs acerca do papel da AOD, apontando para as interseções do seu argumento com a teoria da modernização e a influência dessa linhagem teórica na concepção do autor sobre o papel da ajuda externa no desenvolvimento das sociedades presas na armadilha da pobreza.

Palavras-chave: Jeffrey Sachs; Objetivos de Desenvolvimento Sustentável; Ajuda Oficial para o Desenvolvimento; Teoria da Modernização.

\footnotetext{
Abstract

Since the post World War II, Official Development Assistance (ODA) has become a constant in the development strategies of developed countries to the periphery. This instrument has remained on the development agenda despite changes in world economy and the criticisms

1 Doutor em Ciência Política pela Unicamp; Mestre em Relações Internacionais pelo PPG San Tiago Dantas (UNESP, Unicamp, PUC-SP); Bacharel em História pela UFMG e em Relações Internacionais pela PUC-MG. Professor do Departamento de Relações Internacionais e do Programa de Pós-graduação em Ciência Política e Relações Internacionais da UFPB.

2 Mestranda em Ciência Política pela Unicamp; Bacharel em Relações Internacionais pela UFPB.

Artigo submetido em 04/07/2018 e aprovado em 02/10/2018.
} 
it has suffered. In the 2000s, ODA was reaffirmed politically and theoretically, as the mean of implementation of the UN development goals agendas and through Jeffrey D. Sachs' work. Considering the importance of Sachs in the workings of the international structure of ODA, a closer look at its intellectual production is essential. The objective of this article is to analyze Sachs' perspective on the role of ODA, pointing to the intersections of his argument with the Modernization Theory and the influence of this theoretical perspective in the author's conception on the role of foreign aid in the development of societies trapped in poverty.

Keywords: Jeffrey Sachs; Sustainable Development Goals; Official Development Assistance; Modernization Theory

\section{Introdução}

Desde o pós Segunda Guerra Mundial, o desenvolvimento, tratado como objeto de análise particular ou como problema real a ser enfrentando pelos países, vem adquirindo centralidade nas relações internacionais. O aumento da desigualdade internacional e os efeitos econômicos e sociais das repetidas crises financeiras, além das tragédias humanas produzidas pelos conflitos militares, têm aumentado a preocupação com aspectos sociais e de desenvolvimento na política internacional. Ao longo de mais de sete décadas, o desenvolvimento internacional esteve no centro da agenda das principais organizações internacionais, absorvendo concepções variadas sobre o seu significado e dando sentido concreto a diversas agendas e práticas internacionais voltadas à superação do subdesenvolvimento na periferia (HARMAN; WILLIAMS, 2014; KOEHLER, 2015). Durante esse mesmo período, ajuda internacional, ou Ajuda Oficial para o Desenvolvimento (AOD) ${ }^{3}$, se consolidou como o principal instrumento político e econômico utilizado pelos países desenvolvidos para impulsionar trajetórias de desenvolvimento ou modernização na periferia. A sua prática tem sido amparada por uma percepção, ou pelo menos por uma retórica, de que esse instrumento seria efetivo no auxílio à construção de trajetórias e ciclos autossustentados de desenvolvimento por parte dos países receptores.

3 De acordo com o Comitê de Ajuda ao Desenvolvimento (CAD) da Organização para a Cooperação e Desenvolvimento Econômico (OCDE), Ajuda Oficial para o Desenvolvimento (AOD) é definida como "a ajuda de governos com a finalidade de promover o desenvolvimento econômico e o bem-estar dos países receptores. Ela pode ser bilateral ou fornecida através de agências multilaterais. Essa ajuda pode ser assistência técnica, doação ou empréstimos em condições mais favoráveis". Ver essa definição e outras informações relevantes sobre a temática no site da CAD/OCDE. 
Ao longo da segunda metade do século XX, a AOD foi objeto de importantes debates, passando por mudanças semânticas e de conteúdo na definição de seu significado, além de revisões sobre seu efetivo papel, adequando-se às alterações nas formulações teóricas predominantes sobre desenvolvimento econômico. Da mesma forma que alterações nos objetivos e estratégias dos países doadores impactaram os rumos da evolução e da prática da AOD. Contudo, o que se manteve inalterado, a despeito de um conjunto de leituras e análises críticas à funcionalidade da AOD, foi a sua centralidade como instrumento político dos países desenvolvidos (THORBECKE, 2002).

Após uma drástica redução no volume da AOD no imediato pós Guerra Fria, ela voltou a se reafirmar politicamente no início do século XXI. Uma das principais razões para a refundação do compromisso político com a ajuda, por parte dos países membros da OCDE, foi a aprovação dos Objetivos de Desenvolvimento do Milênio (ODM), no ano de 2000, e do chamado "Consenso de Monterrey"4 dois anos depois. Esse processo deve ser lido como a concretização de uma reorganização teórica e política, iniciada nos anos de 1990, sobre o recorrente problema de como "levar o desenvolvimento aos países atrasados” e como “auxiliá-los nesse processo”. Uma das conclusões foi justamente a recolocação da AOD como instrumento central da agenda de desenvolvimento internacional.

Os Objetivos de Desenvolvimento Sustentável (ODS), aprovados em 2015 para substituir os ODM como agenda global de desenvolvimento, definem, em seu objetivo de número 17, o papel dos países e governos, e especificamente dos países desenvolvidos, na conformação dos meios de implementação dos objetivos e metas acordadas. As primeiras duas metas desse objetivo específico reafirmam a ajuda direcionada às economias periféricas como o instrumento fundamental do processo de desenvolvimento internacional ${ }^{5}$.

4 O Consenso de Monterrey é resultado da conclusão da I Conferência Mundial sobre Financiamento para o Desenvolvimento, realizada no ano de 2002. Dentre os principais resultados está o reconhecimento da necessidade de volumes expressivos de recursos externos para o alcance dos ODM nos países periféricos. Em 2015, foi realizada a III Conferência sobre Financiamento para o Desenvolvimento, que formou a base da Agenda de Ação de Adis Abeba.

5 Objetivo 17 se apresenta como "Fortalecer os meios de implementação e revitalizar a parceria global para o desenvolvimento sustentável”. As metas mencionadas estão definidas da seguinte maneira: Meta 17.1 "Fortalecer a mobilização de recursos internos, inclusive por meio do apoio internacional aos países em desenvolvimento, para melhorar a capacidade nacional para arrecadação de impostos e outras receitas"; e Meta 17.2 "Países desenvolvidos implementarem plenamente os seus compromissos em matéria de assistência oficial ao desenvolvimento, inclusive fornecer 0,7\% da renda nacional bruta em AOD aos países em desenvolvimento, dos quais 0,15\% a 0,20\% para os países menos desenvolvidos; provedores de AOD são encorajados a considerar a definir uma meta para fornecer pelo menos 0,20\% da renda nacional bruta em AOD para os países menos desenvolvidos”. 
Apenas para ilustrar a magnitude desse processo, no ano de 1965, de acordo com dados obtidos no site da OECD, o fluxo bilateral total de AOD, considerando os países do Comitê de Ajuda ao Desenvolvimento (CAD), foi de aproximadamente US \$ 6,5 bilhões, passando para aproximadamente US $\$ 28,8$ bilhões em 1985 e atingindo US $\$ 146,6$ bilhões no ano de 2017. Apesar de toda a importância atribuída à ajuda, desde as primeiras políticas e ações mais sistemáticas para o desenvolvimento no pós-guerra, até a agenda contemporânea dos grandes planos de desenvolvimento das Nações Unidas, as visões e interpretações acerca da efetividade desse mecanismo estão longe de serem consensuais. Vários estudos foram realizados para averiguar e tentar medir os efeitos da ajuda sobre os países receptores; assim como distintas abordagens teóricas têm sido utilizadas para sustentar ou analisar esse objeto.

Diferentemente do discurso predominante, especialmente aquele dos próprios doadores, muitos desses estudos e análises apontam para a ineficácia, ou mesmo para eventuais malefícios, da ajuda como instrumento para o desenvolvimento ${ }^{6}$. O que se pode dizer de antemão é que a permanência desse instrumento como elemento central da agenda internacional para o desenvolvimento, e mesmo o aumento dos volumes de recursos ofertados, não implica automaticamente a construção ou definição de trajetórias de desenvolvimento nos países receptores ou mesmo a melhoria dos indicadores socioeconômicos dos países.

Entretanto, a permanência da AOD na agenda internacional se dá pela reafirmação teórica que a sustenta como forma de conduzir transformações concretas e adequadas nas trajetórias de desenvolvimento dos países ou, ao menos, reduzir as iniquidades mais latentes. Um dos mais influentes nomes que afirmam essa leitura positiva da ajuda internacional é o economista estadunidense

6 Moyo (2009) e Easterly (2006) baseiam suas críticas em premissas liberais e afirmam que ajuda representaria uma excessiva interferência nos mecanismos de livre-mercado - fatores que de fato promoveriam o desenvolvimento. Em seus trabalhos, os autores trazem argumentos de autores importantes da área, como Michael A. Clemens, que mostra não haver impacto de longo prazo da ajuda no crescimento; Michael Hadjimichaele Richard Reichel que identificaram uma relação negativa entre poupança e ajuda; Peter Boone, que por sua vez concluiu que ajuda tem financiado consumo e não investimento; e Peter Bauer, que identifica as falhas ao planejar o desenvolvimento baseado em ajuda externa. Por outro lado, Erick Reinert (2007) apresenta uma crítica fundamentada na perspectiva estruturalista, em que a ajuda estaria servindo apenas para uma economia paliativa, aliviando sintomas do subdesenvolvimento ao passo que permanece como instrumento de controle por parte dos doadores. Amin (1976) apresenta uma crítica marxista, em que a ajuda seria uma forma de manter o status quo de desigualdade entre países, ao mesmo tempo em que atuaria para a expansão imperialista dos países doadores. E Riddel (2007), que realiza um balanço geral do instrumento da ajuda e apresenta também estudos críticos como o do David Sogge e Stephen Browne, que indicam que interesses geopolíticos e comerciais dos doadores são os principais determinantes da alocação de ajuda. 
Jeffrey D. Sachs. Sachs é influente não apenas no mundo acadêmico, mas ator fundamental no processo de organização dos parâmetros políticos para lidar com o problema do desenvolvimento no seio das Nações Unidas. Assim, sua obra e as iniciativas políticas das quais participa são essenciais para entender as fundamentações que baseiam as concepções correntes sobre o papel da AOD nas agendas de desenvolvimento contemporâneas.

O objetivo desse artigo é apresentar uma análise mais detida sobre a perspectiva de Sachs acerca das possibilidades de desenvolvimento dos países periféricos e sobre o papel da ajuda internacional, tendo como referência as interseções do seu argumento com elementos fundamentais da teoria da modernização e a influência dessa linhagem teórica na concepção do autor ${ }^{7}$. Partimos da hipótese, e buscamos confirmar, que a construção argumentativa de Jeffrey Sachs sobre as possibilidades de trajetória de desenvolvimento da periferia (e sobre a importância da ajuda) está fundamentada, em grande medida, em elementos centrais da teoria da modernização. Em especial, nota-se o paralelo com as contribuições de Walt Whitman Rostow e Paul Rosenstein-Rodan, ambos importantes autores vinculados originalmente ao Center for International Studies (CIS) do Massachusetts Institute of Technology (MIT), onde a teoria esteve bastante vinculada à formulação de uma doutrina de política externa (GILMAN, 2003). Para tanto, optou-se metodologicamente pela análise detida dos textos centrais de Jeffrey Sachs que apresentam essa problemática - The End of Poverty: economic possibilities of our time (2005) e The Age of Sustainable Development (2015) - e sua comparação com os elementos centrais dos trabalhos seminais de Walt Rostow e Rosenstein-Rodan sobre o desenvolvimento e o papel da ajuda externa. Ainda, a análise se ampara no trabalho de importantes comentadores, especialmente os que analisaram a trajetória da teoria da modernização.

Cremos tratar de uma questão relevante, na medida em que o cerne argumentativo da teoria da modernização e os projetos e políticas de desenvolvimento nela amparados não produziram os resultados anunciados, inclusive, criando outras vulnerabilidades e problemas estruturais nos países periféricos. Assim, ao assumir aspectos centrais dessa perspectiva, o argumento de Sachs sobre o papel da AOD e sobre como trafegar do subdesenvolvimento e da pobreza para condições de maior bem-estar merecem também uma atenção mais detida. Faz-se necessário questionarmos se os propósitos de desenvolvimento da comunidade internacional,

7 Interessante notar que nas duas principais obras do autor não há referência direta à teoria da modernização ou seus principais autores. 
recentemente reforçados com a aprovação dos ODS, não carregariam parte dos problemas passados.

O trabalho está estruturado da seguinte forma: na próxima seção, será exposta a perspectiva de desenvolvimento da teoria da modernização, destacando alguns elementos chave dos autores mencionados que dialogam com os propósitos do texto; na seguida, apresentaremos o argumento de Jeffrey Sachs, já estabelecendo seus paralelos e divergências com o paradigma da teoria da modernização. Nas considerações finais, são apresentadas algumas análises e uma tentativa de conciliação entre a abordagem de Sachs e a teoria da modernização e seus desdobramentos.

\section{A teoria da modernização e o desenvolvimento da periferia}

A teoria da modernização ganhou robustez e grande destaque acadêmico e intelectual no pós Segunda Guerra Mundial ao ser adotada pelas ciências sociais estadunidenses como mote argumentativo para importantes áreas e departamentos acadêmicos no país. Os estudos sobre a periferia do sistema internacional, em especial os dilemas da possibilidade democrática e as razões, limites e contradições do seu desenvolvimento passaram a ter a teoria da modernização como um importante ponto de partida analítico (GILMAN, 2003; MORAES, 2006). Uma questão de ordem política também permitiu o fortalecimento dessa abordagem como um importante parâmetro de análise da política internacional e dos dilemas do subdesenvolvimento. Como explica Gilman (2003), a ordem mundial bipolar gerou estímulos para uma política externa norte-americana mais incisiva, voltada à garantia de acesso a mercados e recursos, com a ampliação de sua área de influência. Ao mesmo tempo, esse "imperativo político" norte-americano, uma espécie de intervencionismo de mercado, exigia "uma justificativa cientifica" (GILMAN, 2003) $)^{8}$. A teoria da modernização continha os elementos de justificativa científica e moral para consubstanciar uma agenda de política externa que apontasse o caminho da ação norte-americana sobre a periferia, com a justificativa de se estar contribuindo para reorganizar bases sociais e econômicas que impedem o progresso dessas áreas e povos.

8 Expressões extraídas e traduzidas de trecho no idioma original "For geopolitical reasons to be explored in chapter 2, the need to "do something" for postcolonial regions was a political imperative that demanded a scientific justification” (GILMAN, 2003, p.5-6) 
Concretamente, a teoria da modernização estruturou uma forma específica de compreensão dos processos de desenvolvimento. A dicotomia entre o moderno e o atrasado fundou-se na observação concreta do modelo de sociedade dos EUA e de alguns países europeus como a forma mais avançada e adequada, ou seja, como a própria manifestação da modernidade. Enquanto o resto do mundo, afastado por completo desse modelo ou longe de conseguir atingir seus padrões materiais, representaria o atraso. Desenvolvimento, portanto, significaria perseguir e buscar o modelo de organização social, política, econômica e cultural do mundo ocidental, tendo-o como espelho e padrão.

O programa da teoria da modernização tinha, nesse sentido, uma concepção clara: seria “imprescindível mudar inteiramente o modo de ser 'deles', não modernos, fazendo-os mais próximos do 'nós', modernos e norte-americanos" (MORAES, 2006, p. 97). Assim, trabalhava-se com o que Moraes denominou de "imagem destino", em que o fim a ser alcançado, ao ser predeterminado, determinava também o caminho a ser percorrido pelos países em desenvolvimento, por um tipo de mimetismo, a partir do reflexo dos first comers (MORAES, 2006, p. 40). De toda sorte, para os teóricos da modernização, as mudanças demandadas para a tal modernização não se restringiam ao âmbito econômico, mas envolveriam todo um processo de mudanças nas estruturas sociais que caracterizariam, efetivamente, a modernização (GILMAN, 2003).

A existência dessa imagem destino possibilitaria a repetição da trajetória de desenvolvimento dos modernos, dos avançados. Ainda, assumia-se a argumentação de que seguir um modelo histórico existente daria aos países atrasados a condição de aprender com os erros e contradições da trajetória dos modernos e dar saltos e avançar mais rápido para a superação do atraso. Assim, por conseqüência direta da posição de hegemon do pós Segunda Guerra Mundial, mas também por interesse político, os EUA carregariam o fardo e teriam a missão de "modernizar" o mundo subdesenvolvido e pós-colonial - ou seja, levar esses países para o "paraíso a que os EUA chegaram primeiro", mostrar as "virtudes do american way of life", ou simplesmente "aplicar o New Deal em uma escala internacional” (GILMAN, 2003, p. 69 e p. 20) 9

9 Expressões extraídas e traduzidas de trechos no idioma original: "The mission instead was to "modernize" the postcolonial world, to deliver its members to the secular heaven that the United States had pioneered. The aim was to spread the virtues of "the American way of life," an expansive phrase that included culture, technology, sociability, and piety” (GILMAN, 2003, p.69); "They hoped to realize a New Deal on an international scale[...]” (GILMAN, 2003, p.20). 
As duas décadas após a Segunda Guerra Mundial foram marcadas por uma efervescência intelectual para a teoria da modernização. Em 1959, Edward Shils, em um discurso proferido na Conferência de Modernização Política, iniciou a construção de marcos sólidos para uma definição terminológica de modernização. O autor estabeleceu certos parâmetros para distinguir tradicional de moderno, mesmo reconhecendo não ser tão simples observá-los empiricamente.

Nos novos estados, "moderno" significa democrático e igualitário, científico, economicamente avançado e soberano. Estados "modernos" são "welfare states", proclamando o bem-estar de todas as pessoas e especialmente das classes mais baixas como sua principal preocupação. Estados "modernos" são necessariamente estados democráticos, nos quais não apenas as pessoas são o foco e são cuidadas por seus governantes, mas são, também, a fonte de inspiração e orientação desses governantes. Modernidade implica democracia, e democracia nos novos Estados é, acima de tudo, igualitária. A modernidade, portanto, implica o destronamento dos ricos e tradicionalmente privilegiados de suas posições prementes de influência. Envolve a reforma agrária. Envolve uma forma progressiva de tributação da renda. Envolve o sufrágio universal. A modernidade envolve educação pública universal. A modernidade é científica. Acredita-se que o progresso do país depende de uma "tecnologia racional" e, em última instância, do conhecimento científico. País algum poderia ser moderno sem ser avançado economicamente ou progressivo. Ser avançado economicamente significa ter uma economia baseada na tecnologia moderna, ser industrializado e ter um alto padrão de vida. Tudo isso requer (...) investimentos, construção de novas fábricas, construção de estradas e portos, desenvolvimento de ferrovias, esquemas de irrigação, produção de fertilizantes, pesquisa agrícola (...) e pesquisa sobre utilização de combustíveis. "Moderno" significa ser Ocidental sem o ônus de ter que seguir o Ocidente. É o modelo do Ocidente desassociado, de alguma forma, de suas origens geográficas e lócus (SHILS, 1958, apud GILMAN, 2003, p. 1-2) ${ }^{10}$.

10 Tradução de trechos no idioma original: In the new states "modern" means democratic and equalitarian, scientific, economically advanced and sovereign. "Modern" states are "welfare states," proclaiming the welfare of all the people and especially the lower classes as their primary concern. "Modern” states are meant necessarily to be democratic states in which not merely are the people cared for and looked after by their rulers, but they are, as well, the source of inspiration and guidance of those rulers. Modernity entails democracy, and democracy in the new states is, above all, equalitarian. Modernity therefore entails the dethronement of the rich and the traditionally privileged from their positions of pre-eminent influence. It involves land reform. It involves steeply progressive income taxation. It involves universal suffrage. Modernity involves universal public education. Modernity is scientific It believes the progress of the country rests on rational technology, and ultimately on scientific knowledge. No country could be modern without being economically advanced or progressive. To be advanced economically means to have an economy based on modern technology, to be industrialized and to 
Já em 1960, W. Arthur Lewis, outro expoente do pensamento em análise, perseguindo também as causas do desenvolvimento, identificou a imprescindibilidade de alguns fatores: “a) esforço para economizar; b) capacidade de aplicação do conhecimento científico e tecnológico; e c) capital” (LEWIS, 1960 apud MORAES, 2006, p.80). Corroborando a perspectiva de Shils sobre a centralidade de tecnologia na trajetória de modernização, Lewis estabeleceu uma causalidade importante para a teoria da modernização - a necessidade de poupança e de renda para se atingir níveis suficientes de capacidade técnica para o trânsito entre o mundo atrasado e o moderno. Assim, a existência de poupança seria fundamental para ampliar a capacidade de investimento e criar condições para o acúmulo de capitais e aplicação de conhecimento técnico para estimular a inovação e a utilização de recursos naturais em favor do progresso.

Ao longo do desenvolvimento dessa perspectiva, dois autores produziram contribuições fundamentais: W. W. Rostow e Paul Rosenstein-Rodan. Ambos, ex-pesquisadores do Center for International Studies (CIS), serão a base e o eixo utilizado neste artigo. As pesquisas dos dois economistas foram fundamentais para a conformação da teoria da modernização, assim como para a formulação de uma doutrina de política externa para os Estados Unidos, incidindo sobre a estratégia dos programas de ajuda do país. Inclusive, em virtude do momento histórico e do contexto específico da Guerra Fria, o CIS adquiriu um caráter fortemente anticomunista.

Rostow desenvolveu um modelo de análise do processo de desenvolvimento econômico inserido em um quadro de evolução social que ganhou repercussão mundial (GILMAN, 2003). Para Rostow, as sociedades se dividiam em cinco categorias, que corresponderiam a etapas evolutivas do processo de desenvolvimento: (1) a sociedade tradicional; (2) o momento das pré-condições para o arranco; (3) o momento do "arranco"; (4) a marcha para maturidade; (5) e a era do consumo em massa (ROSTOW, 1978). Sua idéia era a formulação de uma teoria geral do processo de desenvolvimento, que, portanto, também deveria ser utilizada "para ajudar a resolver os problemas da pobreza endêmica nos chamados países

have a high standard of living. All this requires planning and the employment of economists and statisticians, conducting surveys to control the rates of savings and investments, the construction of new factories, the building of roads and harbors, the development of railways, irrigation schemes, fertilizer production, agricultural research, forestry research, ceramics research, and research of fuel utilization. "Modern” means being western without the onus of following the West. It is the model of the West detached in some way from its geographical origins and locus” (SHILS, 1958, apud GILMAN, 2003, p.1-2). 
subdesenvolvidos" (GILMAN, 2003, p. 161) ${ }^{11}$. Para isso, identificou fatores que definiriam a "modernização", comparando-os, tal qual um tipo-ideal, às sociedades subdesenvolvidas. Assim, seria possível identificar a ausência desses fatores nessas sociedades, e demonstraria quais seriam os obstáculos ao desenvolvimento (MORAES, 2006).

Por sua vez, Rosenstein-Rodan se dedicou mais detidamente à análise do papel da ajuda externa fornecida pelos países modernos para o desenvolvimento dos países atrasados ou subdesenvolvidos. Seu texto clássico, International Aid for Undeveloped Countries (1961), sintetiza parte dos argumentos desenvolvidos no CIS em defesa do aumento dos fluxos de ajuda dos Estados Unidos para promover o desenvolvimento de países do Terceiro Mundo (GILMAN, 2003). O ponto central da argumentação estaria numa espécie de ciclo produtivo positivo que se iniciaria com uma ampla injeção de recursos - condição necessária para aumentar o nível de capital per capita - que levaria ao aumento dos investimentos produtivos, permitindo o chamado "grande empurrão" (big push) e o alcance do arranco (take-off). A partir desse momento, os países poderiam seguir trajetórias autossustentadas de desenvolvimento.

Por aproximadamente três décadas, a teoria da modernização se estabeleceu não apenas como marco analítico, mas também como fundamentação para vários planos norte-americanos para o desenvolvimento da periferia. O Programa do Ponto IV, parte da Doutrina Truman, e a Aliança para o Progresso para a América Latina, estabeleceram-se sobre marcos muito próximos à teoria da modernização. O famoso discurso de Truman, de 1949, salienta aspectos fundamentais da teoria da modernização.

devemos embarcar em um novo programa ousado para disponibilizar os benefícios de nossos avanços científicos e progresso industrial para a melhoria e o crescimento de áreas subdesenvolvidas [...] Os Estados Unidos são proeminentes entre as nações no desenvolvimento de técnicas industriais e científicas. Os recursos materiais que podemos usar para a assistência de outras pessoas são limitados. Mas nossos recursos imponderáveis em conhecimento técnico estão em constante crescimento e são inesgotáveis. Acredito que devemos disponibilizar aos povos que amam a paz os benefícios de nossa reserva de conhecimento técnico,

11 Tradução de trecho no idioma original "It sought to understand the factors that had spurred growth in the industrial countries in order to use this knowledge to help solve the problems of endemic poverty in the socalled underdeveloped countries” (GILMAN, 2003, p.161). 
a fim de ajudá-los a realizar suas aspirações por uma vida melhor ${ }^{12}$. (TRUMAN, 1949)

Assim, por aproximadamente quatro décadas, a teoria da modernização marcou o campo dos estudos sobre desenvolvimento, assim como fundamentou a política de ajuda dos EUA. Entretanto, no final dos anos de 1970, a teoria da modernização entrou em crise. Nils Gilman aponta que isso foi resultado da própria crise do modelo de nação dos Estados Unidos. Com a crise do New Deal, a Guerra do Vietnã e o aumento da pobreza interna, os EUA colocavam em xeque o projeto que eles preconizavam como um tipo de ideal global (GILMAN, 2003, p. 205). Entretanto, como veremos adiante, o fim da Guerra Fria reavivou parte dos preceitos fundamentais da teoria da modernização, trazendo novos estímulos para uma possível renovação da teoria e para as práticas e sugestões políticas associadas ao planejamento e ajuda internacional (GILMAN, 2003, p. 267).

Algumas questões referentes à crise da teoria da modernização e sua transição para uma versão mais próxima da agenda neoliberal no início do século XXI merecem reflexões mais aprofundadas, entretanto, para os objetivos deste artigo, traremos alguns comentários mais gerais sobre tal processo. A teoria da modernização enfrentou dois "adversários" muito fortes nas décadas de 1970 e que contribuíram com sua crise. Uma dimensão crítica fundamental se refere à emergência de perspectivas teóricas que negaram a caracterização do processo de desenvolvimento como uma escada, um processo linear, em que os países atrasados poderiam seguir e alcançar, ou pelo menos se aproximar, dos níveis de produção e do padrão de vida do mundo desenvolvido. A caracterização do "subdesenvolvimento" como um produto histórico e específico pelos estruturalistas cepalinos questionava o entendimento de que haveria uma linearidade e um trajeto possível de desenvolvimento, amparado pelas experiências dos países modernos, em que a periferia (o mundo subdesenvolvido, nos termos cepalinos) poderia se basear e acessar (FURTADO, 1975; BIELSCHOWSKY, 2000). A teoria da dependência aprofundou essa crítica, apontando os elementos estruturais de perpetuação da desigualdade entre os mundos desenvolvimento e subdesenvolvido.

12 Tradução de trecho no idioma original: "we must embark on a bold new program for making the benefits of our scientific advances and industrial progress available for the improvement and growth of underdeveloped areas (...) The United States is pre-eminent among nations in the development of industrial and scientific techniques. The material resources which we can afford to use for assistance of other peoples are limited. But our imponderable resources in technical knowledge are constantly growing and are inexhaustible. I believe that we should make available to peace-loving peoples the benefits of our store of technical knowledge in order to help them realize their aspirations for a better life. And, in cooperation with other nations, we should foster capital investment in areas needing development” (Truman, 1949). 
Atrelado ao fortalecimento de uma leitura crítica sobre a ordem econômica internacional, países em desenvolvimento e menos desenvolvidos passaram a apresentar demandas por reformas estruturais na economia política internacional que não necessariamente eram tratadas como problemas de desenvolvimento. A chamada Nova Ordem Econômica Internacional (NOEI) trouxe, por exemplo, um conjunto de proposições e demandas por reformas de importantes regras e instituições internacionais que refreavam a capacidade de desenvolvimento autônomo dos países periféricos. Questões referentes a acesso e transferência de tecnologia e reconstrução do regime internacional de propriedade intelectual foram apresentadas e colocadas em discussão (SELL, 1998; ALESSANDRINI, 2010).

Em um sentido teórico contrário, mas com a força necessária para deslocar a teoria da modernização do centro da agenda política global, a emergência do neoliberalismo responsabilizou o Estado pelo problema do subdesenvolvimento - concretamente, um suposto papel alargado do Estado no planejamento e execução das políticas de investimento e na condução da economia. Com isso, o neoliberalismo emergente entrava em colisão direta com parte fundamental dos pressupostos teóricos da Teoria da Modernização, ainda fortemente influenciados pelo sucesso das políticas de planejamento estatal de corte keynesiano. A aceitação do neoliberalismo, por parte das principais agências internacionais de desenvolvimento e pelo Fundo Monetário Internacional (FMI), como plataforma teórica e política para a solução dos problemas da periferia - ainda fortemente abalada pelas crises de finais dos anos de 1970 e pela renegociação das dívidas nos anos de 1980 e 1990 - desestabilizou o protagonismo da teoria da modernização na conformação da agenda de desenvolvimento internacional (BIERSTEKER, 1990).

Outro eixo da crise da teoria da modernização estava estritamente ligado às estatísticas econômicas e sociais globais, que corroboraram parte das críticas sobre os efeitos da AOD. Por mais de três décadas antes da virada do século, presenciou-se um aumento muito rápido do distanciamento entre os países mais ricos e mais pobres, assim como a piora dos dados relacionados à pobreza e vulnerabilidade social nos países da periferia (CHANCEL; HOUGH; VOITURIEZ, 2017). O otimismo atrelado às teses da convergência internacional, especialmente com a Curva de Knutz, foi sendo substituído por uma leitura mais dura da realidade internacional sobre as desigualdades internacionais. Piketty (2013), ao analisar o argumento de Knutz, entende que muito das explicações trazidas - especialmente a crença na diminuição da desigualdade internacional derivada do processo de industrialização - seriam muito mais uma derivação de uma 
posição política diretamente influenciada pela Guerra Fria. Ou seja, buscavase dar algum alento aos países subdesenvolvidos para mantê-los na "órbita do mundo livre".

Assim, o fraco desempenho das experiências de desenvolvimento das periferias, baseadas no planejamento externo e na ajuda financeira dos países desenvolvidos, colocou as bases fundamentais da teoria da modernização, e seu receituário de desenvolvimento consubstanciado no papel da AOD, sob forte pressão. A combinação entre a emergência do neoliberalismo como novo padrão cognitivo e novo modelo de desenvolvimento de organizações internacionais, como o Banco Mundial e o FMI, e a crise econômica fortemente sentida nos países periféricos, criaram as condições para uma necessária reformulação de agendas de desenvolvimento econômico e social.

A década de 1990 e os primeiros anos do século XXI marcaram uma reorganização da agenda de desenvolvimento das Nações Unidas. Ao mesmo tempo em que o neoliberalismo se fortalecia, abordagens focadas na concepção de desenvolvimento humano emergiam e ganhavam espaço na agenda de desenvolvimento internacional. O Relatório de Desenvolvimento Humano do PNUD, publicado originalmente no ano de 1990, apresentou, pela primeira vez, o Índice de Desenvolvimento Humano (IDH) como parâmetro para mensuração do desenvolvimento dos países. Trata-se de uma importante novidade, uma vez que estabelecia uma perspectiva diferente para pensar o desenvolvimento. Perspectiva que negava o padrão desenvolvimentista das décadas posteriores à Segunda Guerra Mundial e enquadrava a necessidade de integrar o humano à agenda neoliberal (FUKUDA-PARR, 2016).

A aprovação dos Objetivos de Desenvolvimento do Milênio (ODM) representou a consolidação dessa simbiose entre neoliberalismo e a concepção de desenvolvimento humano fundamentada na capabilities approach de Amartya Sen. Esse compromisso multilateral de desenvolvimento devolveu à AOD o papel de desenvolvimento global. Para alguns, um desenvolvimento paliativo, como escreve Erik Reinert (2007), justamente por não buscar respostas mais profundas para os problemas do desenvolvimento e usar de meios apenas para minimizar o sofrimento daqueles em situações de maior vulnerabilidade ${ }^{13}$. Independente

13 Para Reinert (2007), apenas o investimento produtivo em setores com competição imperfeita e retornos crescentes permitiria a estruturação de uma política de desenvolvimento real. Nesse sentido, o sistema econômico, comercial e financeiro internacional seria obstáculo para alguns países em desenvolvimento e subdesenvolvidos. A reforma dos mecanismos de alocação de recursos internacionalmente seria mais importante do que o auxílio financeiro para políticas sociais esparsas por meio da AOD. 
das interpretações sobre o conteúdo e a capacidade transformativa dos ODM, o importante para o argumento aqui trazido é que a AOD voltou a ter um papel fundamental, levando a um aumento expressivo dos volumes destinados aos países da periferia a partir de 2001. Da mesma forma, a AOD foi tratada como o principal meio de implementação dos ODM e, quinze anos mais tarde, como principal instrumento político para o alcance dos ODS ${ }^{14}$.

Dentro desse novo contexto, se apresentaram as novas abordagens de desenvolvimento mais próximas da clássica teoria da modernização. De acordo com Nils Gilman (2003), essa nova versão da teoria da modernização manteve o desprezo pelo conhecimento proveniente dos nativos dos países periféricos e pela participação popular. Além disso, permaneceu a preferência por regras universais de desenvolvimento econômico e a exaltação de valores ocidentais, elevando-os a uma posição normativa. Por outro lado, difere da versão tradicional por preterir o papel do Estado como fomentador da modernidade, em prol das ideias neoliberais de penetração das forças de mercado e do livre mercado como agente da modernidade (GILMAN, 2003, p. 271-272). Ou seja, exatamente aquela simbiose mencionada entre neoliberalismo e ações paliativas de desenvolvimento humano, com o apoio da AOD.

Essa nova teoria da modernização carrega nos discursos sobre a AOD as bases mais fundamentais de sua versão original. A perspectiva de desenvolvimento adotada pelos programas de ajuda, que são dominados pelos doadores, baseia-se no seu modelo de sociedade ocidental, democrática e liberal como padrão para todos os países (HJERTHOLM; WHITE, 2000, p. 63).

Na seção seguinte, analisaremos mais detalhadamente a aproximação teórica da formulação teórica e prática de desenvolvimento proposta por Sachs, junto de sua leitura sobre o papel da Ajuda Oficial para o Desenvolvimento, como forma de traçar os elementos marcantes da teoria da modernização enraizados em sua perspectiva.

14 Existem diferenças marcantes entre as duas agendas de desenvolvimento da ONU, assim como grandes diferenças no conteúdo específico voltado à implementação dos objetivos e metas. Entretanto, a AOD permanece como um instrumento central no conjunto de recomendações. 


\section{Etapas do desenvolvimento, armadilha da pobreza e o grande empurrão: qual papel da ajuda?}

Em sua trajetória acadêmica e política, Jeffrey D. Sachs definiu como conceito chave de suas análises e atuação política o problema da extrema pobreza. Sua militância política tem como elemento discursivo central a obrigação ou missão dos países hoje desenvolvidos de acabar com a extrema pobreza e permitir que os países periféricos possam seguir de forma mais fácil o caminho virtuoso do desenvolvimento ${ }^{15}$ (MUNK, 2013). Essa concepção de missão ou destino seria o equivalente a levar a modernidade para todos os países do chamado Terceiro Mundo.

Sachs utiliza uma representação metafórica do progresso e do desenvolvimento econômico como uma escada, em que cada degrau representa a melhoria no bem-estar econômico. O grande desafio contemporâneo residiria no fato de que uma imensa parcela da população mundial, ainda vivendo em situação de extrema pobreza, permanece fora dessa escada (SACHS, 2005, p. 18). Em termos gerais, essa representação proposta por Sachs se assemelha com o modelo "etapista” de desenvolvimento apresentado por Rostow.

A Figura 1 pretende retratar essa aproximação entre os modelos de Sachs e Rostow. Como é possível perceber, a população que está “fora” da escada de Sachs pode ser comparada àquela das chamadas "sociedades tradicionais" de Rostow. De acordo com Rostow, a sociedade tradicional é caracterizada por uma estrutura que se expande dentro de funções de produção limitadas. Por não ter à disposição os avanços da ciência moderna ou níveis elevados de produtividade, estaria limitada a um "teto no nível alcançável do volume de produção per capita" (ROSTOW, 1978, p. 16). Com isso, não haveria condições para o aumento do nível de capital e de investimentos, forçando-os a viverem em condições propícias para a manutenção de um estado de extrema pobreza.

15 É interessante destacar como o autor alterou significativamente sua agenda de trabalho, deixando de lado o papel de economista em planos de estabilização para se dedicar ao que ele autointitulou "missão de acabar com a extrema pobreza”. Sachs fora responsável por planos de estabilização que realizaram terapias de choque em diversos países, como na Bolívia em 1985 e na Polônia em 1989, o que lhe deu a alcunha de “Doutor Choque”. Já no início dos anos de 1990, foi convidado para atuar na crise econômica da Rússia, contudo, o plano resultou em efeitos catastróficos para o país. Apesar de reconhecer esse fato, Sachs acredita que não pode ser responsabilizado por esse fracasso, pois não tinha poder de decisão e muitas de suas ideias não foram aplicadas (MUNK, 2013). 


\section{Figura 1 - A Escada do Desenvolvimento e as Etapas de Desenvolvimento}

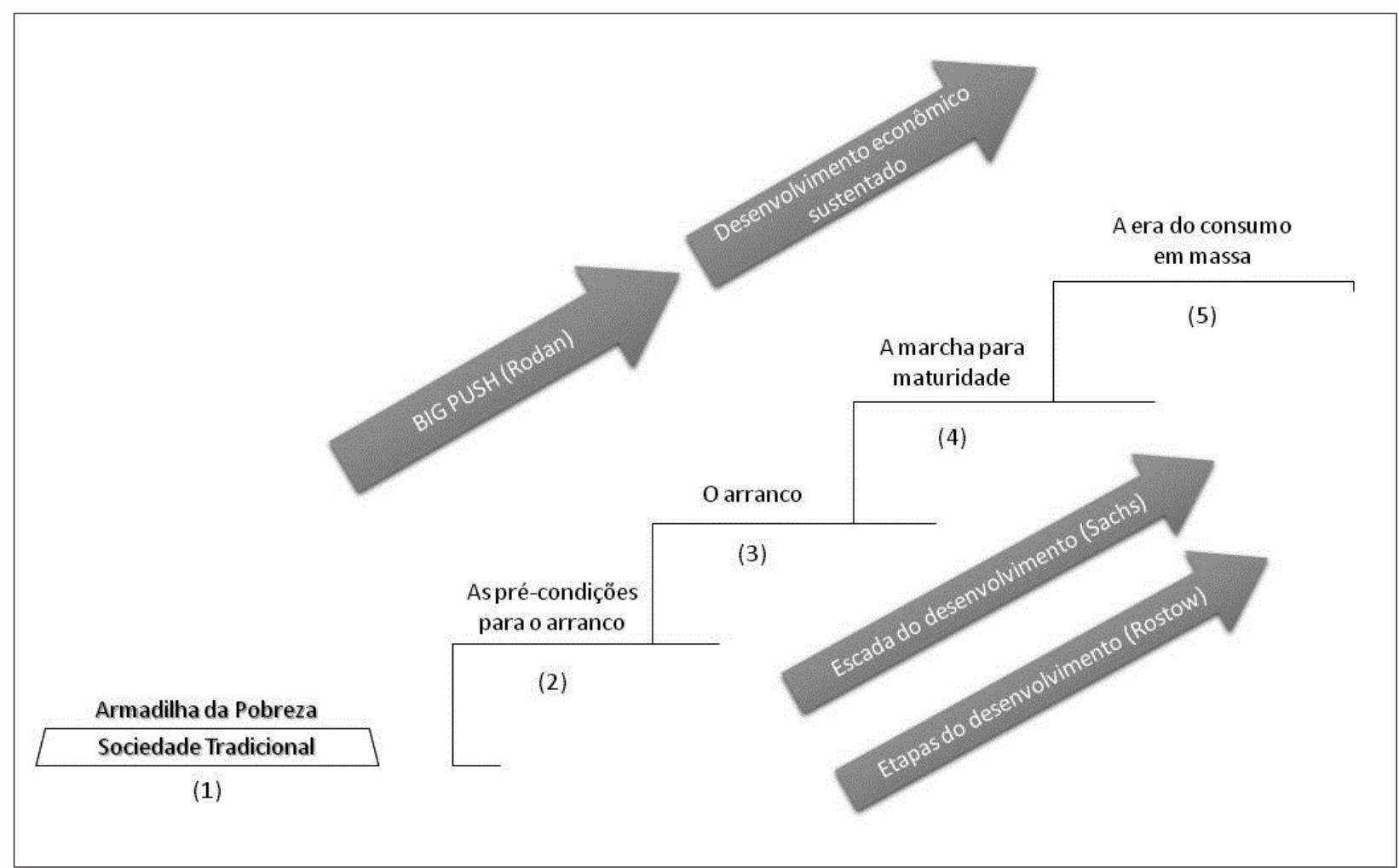

Fonte: elaboração própria a partir de informações obtidas em Sachs (2005) e Rostow (1978).

Sachs considera que a etapa mais difícil do desenvolvimento econômico é a de efetivamente acessar a escada, ou seja, sair da estagnação absoluta caracterizada pela armadilha da pobreza. Quando isso acontece, criam-se as condições básicas necessárias para que o país siga o dinamismo da subida autossustentada. Assim, a proposta de Sachs, de um comprometimento dos países para acabar com a extrema pobreza, tem como objetivo, de um lado, a garantia de condições de vida digna para essas populações e, de outro, dar impulso para o processo de subida, possibilitando o alcance de requisitos mínimos que permitam aos países prosseguirem sozinhos para os próximos degraus (SACHS, 2005).

De acordo com Sachs, para que a subida se inicie e prossiga - ou seja, para que haja desenvolvimento econômico -, é preciso um nível considerável de poupança e investimento. O nível de poupança seria uma condição básica elementar, junto com o aumento das relações comerciais, dos avanços tecnológicos e da utilização de novos recursos na produção. Todos esses fatores impulsionariam a produção e elevariam a renda, o que, por sua vez, estimularia uma constante expansão da poupança e do investimento (SACHS, 2005). Essa perspectiva já havia sido apontada por W. Arthur Lewis e outros autores da teoria da modernização, conforme mencionado na seção anterior. (LEWIS, 1960 apud MORAES, 2006, p. 80). 
Contudo, o mais importante no argumento de Sachs é a afirmação de que as regiões extremamente pobres não conseguem se utilizar desses mecanismos e, portanto, acabam sofrendo com a permanente queda do investimento e do crescimento (em geral, causada pelo atraso tecnológico, declínio no uso de recursos naturais, choques de produtividade e redução da produção, renda e poupança). A explicação para a permanência dessa situação se encontra em problemas mais complexos, divididos em oito categorias, sendo que o primeiro deles é exatamente a armadilha da pobreza ${ }^{16}$ (SACHS, 2005).

Assim, de uma forma circular, a pobreza seria a própria causa da pobreza, ou da estagnação econômica. As populações extremamente pobres carecem de capital e não há margem na renda que exceda os valores para atendimento de suas necessidades básicas, o que os impede de poupar para investir em mais capital (SACHS, 2005, p. 56). Portanto, a essência da armadilha da pobreza é que "os extremamente pobres são demasiado pobres para poupar para o futuro e assim acumular o capital por pessoa que poderia retirá-los na atual situação de miséria" (SACHS, 2005, p. 56-57) ${ }^{17}$.

Sachs, como os teóricos da modernização, também considera que outros aspectos, além dos fatores estritamente econômicos, são fundamentais para o desenvolvimento. Ou seja, há uma série de elementos que podem inicialmente obstar a caminhada para a modernidade, caso não observados. Para propriamente analisar todos esses fatores e traçar um plano de desenvolvimento que seja responsivo às necessidades locais, Sachs propõe um método denominado de "economia clínica", em que uma espécie de checklist com oito categorias deve ser observada de modo a realizar o que ele denomina de "diagnóstico diferenciado" (SACHS, 2005, p. 75). A proposta de Sachs é de que as agências que estão atuando para promover o desenvolvimento econômico em outros países realizem inicialmente esse checklist, para identificar quais os fatores que, naquela localidade, estariam provocando a estagnação econômica. Tal método se assemelha ao estudo realizado por Rostow para caracterizar cada etapa de desenvolvimento. Rostow, após identificar os fatores que explicariam a modernização, comparou-os com a realidade das sociedades tradicionais, identificando quais fatores estariam ausentes e quais seriam obstáculos, conforme supramencionado (MORAES, 2006, p. 88).

16 Os demais seriam: geografia física; armadilha fiscal; falhas na governança; barreiras culturais; geopolítica; falta de inovação; armadilha demográfica. A armadilha da pobreza é o ponto central do argumento e as demais categorias atuam para aprofundar a situação.

17 Tradução de trecho no idioma original "They are too poor to save for the future and thereby accumulate the capital per person that could pull them out of their current misery” (SACHS, 2005, p.56-57) 
Dessa forma, é possível identificar, nos argumentos de Sachs, a pretensão dos teóricos modernos de querer ditar um caminho considerado ideal, que deva ser percorrido pelos países periféricos. Isto é, a ideia de que é possível pensar o destino das nações mais pobres como um reflexo dos países ocidentais. Ademais, observam-se tentativas universalistas em ambos: Sachs não só afirma deter o conhecimento e o modelo a ser seguido, como também acredita que esse modelo deve ser aplicado em todos os países que ainda convivem com a extrema pobreza. É verdade que, em seu método da economia clínica e diagnóstico diferencial, Sachs abre uma margem para que a realidade local seja analisada. Contudo, isso não altera o fato de que há apenas um modelo de sociedade que é visto como o melhor e mais adequado. A análise do contexto local não abre espaço para novos modelos de desenvolvimento, mas sim para compreender quais especificidades locais devem ser dissolvidas para viabilizar o processo de transformação da sociedade para o modelo definido.

Ainda analisando o modelo proposto por Jeffrey Sachs, é importante ressaltar que, mesmo que as comunidades conseguissem identificar todas essas questões que as estariam impedindo de avançar, não conseguiriam sair da extrema pobreza porque "são muito pobres para resolver os seus problemas sozinhos. E os seus governos também são" (SACHS, 2005, p. 242) ${ }^{18}$. Isto é, eles não possuem a quantidade de capital para realizar as intervenções identificadas. Sachs refere-se a seis tipos de capital: 1) capital humano; 2) capital de negócios; 3 ) infraestrutura; 4) capital natural; 5) capital público institucional; 6) capital de conhecimento.

O problema é que a população mais pobre já inicia sua vida com um baixíssimo nível de capital per capita, e geração após geração essa taxa tende a cair, dado o fato de estarem presos na armadilha da pobreza. Uma família já empobrecida possui uma renda que mal atende às suas necessidades básicas, conseqüentemente, não sobram recursos para poupar e investir, bem como para pagar impostos. Dessa forma, sem poupança privada e com o enfraquecimento do orçamento público, nem os indivíduos nem o governo conseguem alcançar capacidade de investimento significativo. Há um declínio no nível de capital per capita, que é ainda agravado pela depreciação do capital e pelo crescimento populacional. O resultado disso é um crescimento econômico negativo, mantendo as rendas das famílias em um nível mínimo, impedindo o mecanismo de acumulação e perpetuando a pobreza (SACHS, 2005, p. 248).

18 Tradução nossa do trecho no idioma original "But they are too poor to solve their problems on their own. So, too, are their own governments” (SACHS, 2005, p.242) 
A quebra desse ciclo, ou seja, a quebra da armadilha da pobreza, se daria com a provisão de recursos provenientes da AOD. A ajuda externa atuaria para suprir a lacuna financeira identificada por meio de três canais: a) uma parte deveria ser direcionada para as famílias empobrecidas, de modo a atender às suas necessidades básicas; b) a maior parcela da ajuda seria destinada para o orçamento do governo, para financiar os investimentos públicos e; c) a ajuda seria enviada para auxiliar os negócios privados, através de microfinanças ou outros programas semelhantes (SACHS, 2005, p. 246).

Assim, para Rostow, Rosenstein-Rodan e Sachs, a ajuda advinda de fontes externas teria o papel de dar um grande empurrão (big push), nos termos de Rosenstein-Rodan, por meio da injeção de capital que iria romper a armadilha da pobreza, permitir acumulação, investimentos e possibilitar a saída da forma tradicional de organização societal e econômica. Tais investimentos representariam a subida para o primeiro degrau da escada, ou, em outras palavras, a criação das précondições para o arranco, conforme a Figura 1. De acordo com Sachs, “investimentos em educação básica, saúde, infraestrutura e agricultura, podem possibilitar que uma família, ou uma região mais pobre, ganhe renda adicional e riqueza suficiente para financiar o próximo estágio de desenvolvimento” (SACHS, 2015, p. 171) ${ }^{19}$.

Interessante como Rostow conceituou de forma muito clara essa relação complexa que deve se estabelecer entre sociedades modernas e atrasadas para a superação das dificuldades inerentes à subida na escada. Para o autor, esse processo seria uma “era de transição em que uma sociedade se prepara - ou é preparada por forças externas - para o desenvolvimento sistemático” (ROSTOW, 1978, p. 31). Continuando, Rostow considerava que a ajuda externa proveria uma grande vantagem para os países da periferia, que poderiam contar com esse instrumento para facilitar o processo de desenvolvimento. Ele afirma que “o auxílio internacional sob a forma de assistência técnica, empréstimos suaves ou subsídios [...] são um aspecto singular do panorama moderno" com que os países que se desenvolveram décadas antes não contavam (ROSTOW, 1978, p. 169-170). Da mesma forma como tratado por Sachs para o cenário atual, Rostow entendia que, apesar de ter esse grande potencial, os níveis de ajuda externa da sua época eram extremamente inadequados e não atenderiam às necessidades de ultrapassar o crescimento demográfico (ROSTOW, 1978, p. 171).

19 Tradução de trecho no idioma original "By that I mean that key investments in basic education, health, infrastructure, and farming can enable a poor household, or indeed a poor region, to earn enough added income and garner enough wealth to be able to finance the next stage of development” (SACHS, 2015, p.171). 
Assim, para Jeffrey Sachs, mas também para Rostow, se a ajuda for direcionada em quantidade suficiente e de forma sustentada, com previsibilidade por certo período de tempo, o estoque de capital aumentaria a ponto de permitir que as famílias tenham uma renda que exceda o seu consumo, levando à poupança e a maiores investimentos. Além disso, o pagamento de impostos fortaleceria o orçamento público (SACHS, 2005, p. 246). Em conformidade com Sachs, Rostow afirmava que tão relevante quanto a quantidade de ajuda era a sua continuidade e previsibilidade (ROSTOW, 1978, p. 171).

Durante a fase das pré-condições, a sociedade passa por diversas mudanças, mas uma questão central para Rostow era a passagem de uma sociedade predominantemente agrícola para uma industrial e comercial. A razão fundamental dessa ênfase está no fato de que esses são setores passíveis de maior aplicação de tecnologias modernas que permitam rápido crescimento, alta taxa de reinvestimento e lucros (ROSTOW, 1978, p. 166). Após todas as pré-condições estabelecidas, a sociedade seria impulsionada para o degrau do "arranco". Como definido por Rostow, essa fase é o momento em que "o desenvolvimento passa a ser a condição normal" e "ganha regularidade e capacidade de fortalecer a si mesmo" (ROSTOW, 1978, p. 52-53). Essa fase produz mudanças nos mais diversos setores da sociedade, desde a organização da produção até os valores sociais em geral (ROSTOW, 1978, p. 78). Vale salientar, contudo, que para que o padrão de crescimento autossustentado seja iniciado, o arranco tem que ser bem-sucedido e, para isso, deve-se contar com amplo fluxo de capital (GILMAN, 2003, p. 196-197). Portanto, a ajuda deve permanecer até que esse processo seja exitoso, isto é, quando as engrenagens para a sua continuidade autossustentada estejam estabelecidas.

De acordo com Sachs, o país deverá contar com a ajuda durante a sua subida até que chegue a condição de Estado de renda média (SACHS, 2015, p. 171). Isso porque, para ele, países de renda média não precisam mais dos programas de ajuda para acabar com a extrema pobreza, pois já se beneficiam do dinamismo do crescimento, isto é, passaram do arranco. A partir da fase do arranco, o país continuará sua subida para alcançar níveis cada vez maiores de desenvolvimento. Sachs afirma que, ao longo desse caminho, a sociedade "desfrutará do crescimento autossustentado que eventualmente levará ao fim da extrema pobreza” (SACHS, 2015, p. 171) 20.

20 Tradução de trecho original "enjoying self-sustaining growth that eventually will lead to the end of extreme poverty” (SACHS, 2015, p.171). 
Jeffrey Sachs, que iniciou sua carreira como economista no final da década de 1970, já em um momento de crise do modelo da teoria da modernização, tornouse adepto da economia neoliberal, que viria a dominar os anos subsequentes. Assim, o argumento de Sachs deve ser compreendido dentro do campo mais contemporâneo das teorias econômicas que ganharam força no pós Guerra fria. Isso é relevante para compreendermos partes das divergências com o modelo de Rostow. Uma delas é que, apesar de reconhecer a importância da industrialização, ela não aparece como solução para acabar com a extrema pobreza. Além disso, o foco nas mudanças estruturais é substituído pela acumulação de capital e pelos mecanismos de mercado. De acordo com Sachs, "quando as pré-condições de infraestrutura básica [...] e capital humano [...] estão postas, mercados são mecanismos poderosos o suficiente para o desenvolvimento" (SACHS, 2005, p. 3 ) $^{21}$. Assim, há diferenças sutis, mas importantes, entre o argumento contemporâneo de Sachs e os teóricos tradicionais da modernização. Rostow e outros teóricos da modernização escreveram em um contexto de auge do Estado de bem-estar social, onde o Estado forte é que atuava como fomentador da modernização e havia um grande foco na estrutura produtiva. Nesse caso, a industrialização era promovida como uma das principais estratégias para atingir os objetivos de desenvolvimento.

A análise dos elementos centrais do argumento de Sachs e, especialmente, da forma como entende o papel da AOD, é determinante para compreendermos um capítulo fundamental da agenda contemporânea de desenvolvimento. Como afirmado na introdução deste texto, Jeffrey D. Sachs é um ator político importante na definição da agenda de desenvolvimento do sistema das Nações Unidas. Nos anos 2000, Sachs assumiu papel de assessor especial para os Objetivos de Desenvolvimento do Milênio e tornou-se diretor do Columbia's Earth Institute, da Universidade de Columbia; mesmo período em que publicou seu livro The End of Poverty: the economic possibilities of our time (2005), no qual sistematizou os argumentos analisados acerca da factibilidade e dos caminhos para a erradicação da extrema pobreza. Posteriormente, participou da criação do Sustainable Development Solutions Network (SDSN), a rede global que pensou a formulação dos Objetivos de Desenvolvimento Sustentável (ODS). Nesse novo contexto, Sachs publicou sua outra obra também fundamental para a compreensão

21 Tradução de trecho no idioma original "When the preconditions of basic infrastructure (roads, power, and ports) and human capital (health and education) are in place, markets are powerful engines of development." (SACHS, 2005, p.3). 
da sua interpretação sobre desenvolvimento e o papel da AOD: The Age of Sustainable Development (2015). Através de todos esses canais, o economista atuou politicamente na estruturação de importantes iniciativas voltadas a dar centralidade à ajuda, assim como seus trabalhos acadêmicos buscam sustentar analiticamente a prática da AOD como instrumento para o desenvolvimento e como meio de implementação dos grandes planos de desenvolvimento da ONU.

\section{Considerações finais}

A Ajuda Oficial para o Desenvolvimento mantém-se como um dos principais instrumentos utilizados pelos países desenvolvidos para impulsionar trajetórias de desenvolvimento nos países periféricos. Esse é um fato que permanece, a despeito de diversas análises teóricas e pesquisas empíricas que demonstrariam a ineficácia da ajuda ou mesmo seus efeitos maléficos para o desenvolvimento. A prática da AOD se sustenta na contemporaneidade, por meio da reafirmação política de seu uso, como meio de implementação dos Objetivos de Desenvolvimento Sustentável (ODS), e pela sua reafirmação teórica, presente principalmente nos trabalhos do economista Jeffrey D. Sachs.

De acordo com Sachs, o grande problema do desenvolvimento global é que uma imensa parcela da população mundial se encontra fora da "escada de desenvolvimento", presa na chamada "armadilha da pobreza" - esses seriam os extremamente pobres que não conseguem acumular capital acima do nível necessário para a sua sobrevivência. Nesse contexto, a AOD seria imprescindível para dar uma injeção de capital que elevaria os níveis de capital da sociedade de modo a permitir a acumulação e os investimentos básicos, que quebrariam a armadilha da pobreza. Dessa forma, poderiam alcançar o primeiro degrau da escada de desenvolvimento, e seguir sua subida sustentada até os patamares das sociedades hoje desenvolvidas.

Nesse trabalho, buscamos apresentar o argumento do economista Jeffrey Sachs e demonstrar que sua perspectiva se encontra, em grande medida, fundamentada nas premissas básicas da teoria da modernização. Jeffrey Sachs reafirma a proposta de pensar o desenvolvimento como uma trajetória em que se estabelece uma imagem-destino a ser perseguida pelos atrasados, mantendo a presunção básica dos teóricos da modernização de existência de um modelo de sociedade almejado. Em 
ambos os modelos, o subdesenvolvimento e as condições da sociedade tradicional são compreendidas como etapas anteriores que precisam ser superadas para se seguir em direção ao desenvolvimento.

A alegoria da escada marca uma clara convergência com as etapas de desenvolvimento de Rostow. Sachs, bem como os teóricos da modernização, preconiza que no caminho a ser percorrido, os países periféricos - ou as sociedades tradicionais - devem contar com o auxílio dos países desenvolvidos, que já chegaram aos mais altos degraus. Esses pioneiros indicariam as políticas e ações que deveriam ser aplicadas e enviariam a ajuda externa necessária para permitir o grande empurrão.

Assim, é notável que a AOD se encontra fundamentada em uma perspectiva teórica que possui elementos da teoria da modernização. Contudo, a abordagem de Sachs e dos programas de ajuda da atualidade devem ser compreendidos dentro de uma perspectiva que dialoga com o cenário político, econômico e intelectual do pós Guerra fria. Mesmo reformulada, a teoria da modernização mantém as bases de sua versão original, mas substitui o Estado forte e industrializante pelas forças de mercado. Nesse sentido, sob a roupagem da luta contra a extrema pobreza, a teoria da modernização retorna ao debate sobre desenvolvimento e sobre a prática da ajuda e tem ocupado espaços cada vez mais relevantes.

\section{Referências}

ALESSANDRINI, Donatela. Developing Countries and the Multilateral Trade Regime. The failure and Promisse of the WOT's Development Mission. Oxford and Portland, Oregon, 2010.

AMIN, Samir Unequal Development: an Essay on the Social Formations of Peripheral Capitalism. The Harvester Press Limited/Monthly Review Press, 1976.

BIELSCHOWSKY, Ricardo. Cinqüenta Anos de Pensamento na CEPAL. Rio de Janeiro: Record, 2000.

BIERSTEKER, Thomas. "Reducing the Role of the State in the Economy: a conceptual exploration of the IMF and World Bank Prescriptions”. International Studies Quarterly. Vol.43, n.04, 1990.

CHANCEL, Lucas; HOUGH, Alex; VOITURIEZ, Tancrede. Reducing Inequalities within Countries: Assessing the Potential of the Sustainable Development Goals. Global Policy, vol. 9, n. 01, 2017. 
EASTERLY, William. The White Man's Burden. Penguin Group, 2006.

FUKUDA-PARR, Sakiko. "From the Millennium Development Goals to the Sustainable Development Goals: shifts in purpose, concept, and politics of global goal setting for development”. Gender and Development, vol. 24: 01, p. 43-52, 2016

FURTADO, Celso. O Mito do Desenvolvimento Econômico. Paz e Terra: Rio de Janeiro, 1975.

GILMAN, Nils. Mandarins of the Future. Modernization Theory in Cold War America. The Johns Hopkins University Press, 2003.

HARMAN, Sophie; WILLIAMS, David. International Development in Transition. International Affairs, vol. 90, n. 04, 2014.

HJERTHOLM, Peter; WHITE, Howard. Foreign aid in historical perspective: background and trends In. TARTP, Finn (ed) Foreign Aid And Development-Lessons learnt and directions for the future. Routledge: New York, 2002.

KOEHLER, Gabriele. Seven Decades of Development, and now what. Journal of International Development, vol. 27, n. 06, 2015.

MAYMÍ-SUGRAÑES, Héctor. Cold Warriors: Advancing the Library Modernizing Model in Latin America. Investigación Bibliotecológica, Vol. 31, N. 72, 2017.

MORAES, Reginaldo C. C. Estado, Desenvolvimento e Globalização. Editora Unesp. São Paulo, 2006.

MOYO, Dambisa. Why aid is not working and how there is a better war for africa. Fsg, 2009.

MUNK, Nina. The Idealist: Jeffrey Sachs and the Quest to End Poverty. Anchor. Setembro, 2013.

PIKETTY, Thomas. O Capital no Século XXI: Intrínseca, 2014.

REINERT, Erik S. How Rich Countries Got Rich... and Why Poor Countries Stay Poor. Constable 2007.

RIDDELL, Roger C. Does Foreign Aid Really Work? Oxford University Press, 2007.

ROSENSTEIN-RODAN, Paul N. Natura non Facit Saltum: Analysis of Disequilibrium

Growth Process. In. MEIER, G. M. SEERS, D (ed.). Pioneers in Development. Oxford University Press, 1984.

ROsTOW, W.W. Etapas do desenvolvimento econômico- A non-communist manifesto. Cambridge University Press, 6ed, 1978.

SACHS, Jeffrey D. The Age of Sustainable Development. Columbia University Press, 2015. SACHS, Jeffrey D. The End of Poverty: Economic Possibilities for our Time. Penguin Press, 2005. SELL, Susan. Power and Ideas: North-south politics of Intellectual Property Rights and Antitrust. State University of New York Press, 1998.

THORBECKE, Erick. The Evolution of the Development Doctrine and the role of foreign aid, 1950-2000. In. TARTP, Finn (ed) Foreign Aid And Development-Lessons learnt and directions for the future. Routledge: New York, 2002.

TRUMAN, Harry. Truman's Inaugural Address. January 20, 1949. Disponível em: < https:// www.trumanlibrary.org/whistlestop/50yr_archive/inagural20jan1949.htm > . 